Research article

\title{
Preoperative Acute Normovolaemic Hemodilution (ANH) in combination with Hypotensive Epidural Anaesthesia (HEA) during knee arthroplasty surgery. No effect on transfusion rate. A randomized controlled trial [ISRCTN87597684] Palle Juelsgaard*, Marianne Birkebæk Møller and Ulf Thyge Larsen
}

Address: Dept. Of Anaesthesiology, Aarhus Amtssygehus, Aarhus University Hospital, Tage Hansensgade, DK-8000 Aarhus C, Denmark E-mail: Palle Juelsgaard* - juelsgaard@dadlnet.dk; Marianne Møller - henrikmarianne@ofir.dk; Ulf Larsen - ulfthyge.Larsen@aas.auh.dk *Corresponding author

Published: 18 April 2002

BMC Anesthesiology 2002, 2:1
Received: 18 September 200 I

Accepted: 18 April 2002

This article is available from: http://www.biomedcentral.com/I47I-2253/2/I

(c) 2002 Juelsgaard et al; licensee BioMed Central Ltd. Verbatim copying and redistribution of this article are permitted in any medium for any purpose, provided this notice is preserved along with the article's original URL.

\begin{abstract}
Background: Hypotensive epidural anaesthesia (HEA) combines a high epidural anaesthesia, performing a sympathetic blockade, with low-dose iv-infusion of epinephrine to stabilize circulation in the conscious patient. Mean artery blood pressure is reduced to $45-50 \mathrm{mmHg}$ and hereby a reduced blood loss. In this study we have combined HEA with preoperative acute normovolaemic hemodilution (ANH) in attempt to further reduce the blood loss and need for blood transfusion in total knee arthroplasty surgery (TKR).

Methods: Twenty-eight patients scheduled for TKR are randomised to ANH or no hemodilution (non-ANH). Both groups are anaesthetized with HEA. ANH is established with predonation of 20 $\%$ of the total blood volume, and replacement with equal volume of HAES $6 \%$. Blood re-transfusion is completed within $6 \mathrm{~h}$.

Results: A mean of $877 \mathrm{ml}$ blood was predonated (19.7 \% of the total blood volume). Blood loss was, except from the intraoperative loss, significantly higher in ANH group. The total loss was I306 $\mathrm{mL}(\mathrm{ANH})$ vs. $1026 \mathrm{~mL}$ (non-ANH), $\mathrm{p}<0.05$. Except from the first hour postoperatively, hematocrit was identical in between groups postoperatively. The amount of blood transfusion was identical $386 \mathrm{ml}(\mathrm{ANH})$ vs. $343 \mathrm{ml}$ (non-ANH) (ns). $50 \%$ went through surgery without receiving blood (ANH) vs. $58 \%$ (non-ANH). No renal, neurological or cardiopulmonary complications were registered.

Conclusions: These data suggest no benefits in combining HEA and ANH in TKR surgery. Probably because of the reduced viscosity of the blood after $A N H$, there is an increased postoperative blood loss. The need for homologous blood transfusion was identical.
\end{abstract}

\section{Background}

The risks associated with banked homologous blood products are well known. These risks include among others: ABO incompatibilities, viral or bacterial infections, and immunosuppression [1]. Immunomodulation may have long lasting effects on the patient who has received a single unit of homologous blood, and may alter the immune response in a way that may render the recipient vul- 
nerable to infection [2]. Several techniques for management of surgical patients without homologous blood transfusion are available. Acute normovolaemic hemodilution (ANH) is the simultaneous exchange of whole blood with an identical volume of an iso-oncotic colloid. The resulting dilutional anaemia is compensated for by an increase in cardiac output and enhanced arterial oxygen extraction. Although bleeding during surgery remains essentially unchanged, blood lost during the surgical procedure contains fewer red cells because the patient's blood has been diluted. At the conclusion of surgery or when needed, donated blood may be returned to the patient [3]. ANH is found to be effective in surgical cases with a high-expected blood loss [4]. The concept of decreasing the arterial blood pressure to hypotensive levels during anaesthesia and surgery has been used for decades in attempt to reduce intraoperative blood loss and to improve conditions in the surgical field. A mean arterial blood pressure (MAP) of 55-60 mmHg has been regarded as the lowest safe level in young healthy patients, one of the reasons being that this range represents the lowest MAP at which auto regulation of the cerebral blood flow is still active.

Sharrock introduced the hypotensive epidural anaesthesia (HEA) in 1989 [5]. Epidural anaesthesia was used to establish a sympathetic blockade, causing a hypotensive state. Low dose of epinephrine was infused to maintain and stabilize cardiac output and heart rate. During HEA, a MAP of 45-50 mmHg was allowed since the cerebral condition could be monitored through the patient's ability to communicate, as only slight sedation was used. HEA is a safe technique with a low complication - and mortality rate, even in patients with left ventricular dysfunction [68]. This method reduces blood loss and need for transfusions significantly in hip arthroplasty surgery [9]. We have in a previous paper demonstrated a reduced perioperative blood loss at $47 \%$ in knee arthroplasty surgery (TKR) during HEA [10].

The aim of this study was to evaluate the potential benefits of a reduced need for homologous blood transfusion by combining HEA and ANH in TKR surgery.

\section{Methods}

The study was approved by the regional scientific ethics committee and corresponds with the Helsinki II declaration. In all patients written informed consent was obtained.

Twenty-eight patients scheduled for primary cemented TKR surgery were included in the study period. Exclusion criteria were: Patients underage ( $<18$ years), hematocrit $<$ 0.30 , recent myocardial infarction ( $<6$ months), unstable angina, diagnosed and clinical symptomatic aortic- or mi- tral valve stenosis (>30 mmHg), previous stroke, unmedicated hypertension and treatment with beta-antagonists or anticoagulants. No patient was medicated with salicylate or nonsteroidal anti-inflammatory drugs in the two weeks prior to surgery.

On the day of surgery patients were consecutive and blindly randomised to HEA with or without ANH using computerised randomisation to two treatments (MedStat ${ }^{\circledR}$.

ANH was performed by drawing $20 \%$ of the total blood volume through a venous cannula immediately before anaesthesia. This volume was simultaneously replaced with an equal volume of Hydroxy Ethyl Starch $6 \%$ (HAES 6 $\%)$. The following formula was used:

Total blood volume = body weight $(\mathrm{kg}) \times 60 \mathrm{~mL}$ per $\mathrm{kg}$.

The donated volume of blood was collected in transfusion bags together with a stabilizer. Until re-transfusion in the recovery room, the blood was storaged in a cooler box. Retransfusion was terminated within 6 hours. Both groups were anaesthetized with the hypotensive epidural anaesthesia technique.

\section{HEA}

To establish the sympathetic blockade, epidural anaesthesia was performed at the Th12-L1/L1-L2 interspace with ropivacaine $1 \%, 25-35 \mathrm{ml}$ to achieve analgesia at Th1-2 dermatome. For epidural infusion, ropivacaine 1\% 6-8 $\mathrm{ml} / \mathrm{h}$ was used until end of surgery. The infused dose varied according to the patient's age, height and weight. The arterial pressure decreased progressively over 10 minutes after the epidural bolus injection to a MAP of $45-50 \mathrm{~mm}$ $\mathrm{Hg}$. In case of insufficient decrease in blood pressure, bolus ropivacaine $5 \mathrm{ml}$ epidurally was used. Infusion of epinephrine $0.01-0.07 \mu \mathrm{g} / \mathrm{kg} / \mathrm{min}$ was started immediately after insertion of the central vein catheter; in order to prime the catheter before the sympathetic blockade was established. During surgery sedation with propofol was adjusted to a level where communication was possible. Intraoperative infused fluid volume was in both groups isotonic saline $5 \mathrm{~mL} / \mathrm{kg} / \mathrm{h}$ as basic need and Isotonic saline three times the amount of blood loss as substitution for intraoperative blood loss. Oxygen was delivered at $3 \mathrm{l} /$ min on a nasal catheter. All patients were kept warm, using a Bair-hugger. No knee tourniquet was used.

Monitoring: 5-lead ECG, pulse oximetry, respiratory rate, end-tidal $\mathrm{CO} 2$, radial- and central venous pressures. All data were continuously recorded on a computer, using the Datex Collect (software (Datex, Denmark). 
Infusion of epinephrine was continued postoperatively until MAP reached $75 \mathrm{mmHg}$, hereafter epinephrine was reduced gradually until removal. In both groups, the intraoperative blood loss was determined by measurement of the volume in the suction apparatus, and by weighing of towels. The postoperative blood loss was determined by measuring the drainage for 48 hours after operation. Drains were removed after 48 hours.

Postoperative analgesia was performed as patient controlled epidural analgesia using ropivacaine $0.2 \%$ and morphine $0.05 \mathrm{mg} / \mathrm{ml}$ for three days, according to our normal routine. The epidural catheter was removed on the third postoperative day. Hereafter the patients were treated orally with morphine and acetaminophen. Fragmin ${ }^{\circledR}$ was given as thrombo-prophylaxis. All patients used a continuous passive knee motion apparatus the first two postoperative days.

The patients were anaesthetized by one of the three anaesthesiologist authors and operated by two surgeons. Demographics, hematocrit pre- and post ANH, at arrival at recovery room, and at 1., 2., 3., and 5. postoperative day were recorded. Intra- and postoperative fluid- and blood transfusions were also registered. Blood transfusion was indicated when the hematocrit value was below $28 \%$.

\section{Statistics}

After passing through the exclusion criteria patients were consecutive and blindly randomised to HEA with or without ANH using computerised random numbers for 2 treatments (MedStat ${ }^{\circledR}$ ). The result of the randomisation was known immediately before anaesthesia.

Data are presented as means (SD) or means (range). Comparison between groups was performed with a Student's ttest. For ASA-score a Mann Whitney's test was used. Chitest was applied on gender and the fraction of transfused patients in the two groups. A p $<0.05$ was chosen as significance level.

The sample size of this study was determined by an expected effect of ANH on blood transfusion rate of $50 \%$ (MIREDIF). $\alpha=5 \%, \beta=10 \%, \mathrm{SD}=400$

$\mathrm{n}_{1}=\mathrm{n}_{2}=2\left(\mathrm{t}_{2}\left(+\mathrm{t}_{\beta}\right)^{2} \mathrm{SD}^{2} /\right.$ MIREDIF $^{2}$

Power $=(1-\beta)=1-0.10=0.90$

This calculation resulted in 13 patients in each group. We decided to enrol 14 in each group.

\section{Results}

In all 33 patients were screened to enter this study. Three patients were excluded because of treatment with beta-antagonists and 2 patients because of previous stroke.

Twenty-eight patients, 14 ANH and 14 non-ANH were enrolled in the study. Patient characteristics and preoperative blood measurements are shown in Table 1. Except from the preoperative mean artery blood pressure (measured before blood donation) there was no significant difference in between groups. Intraoperative values are shown in Table 2. The ANH group was given ropivacaine $1 \%$, mean $288 \pm 32 \mathrm{mg}$ and non-ANH ropivacaine $1 \%$, $297 \pm 22 \mathrm{mg}$ (ns). The intraoperative mean artery blood pressure was identical between groups. MAP demonstrated a reduction of $53.4 \%$ (ANH) and of $58.4 \%$ (non$\mathrm{NAH}$ ), compared to preoperative blood pressure (ns).

Table I: Demographics and preoperative measurements of the patients.

\begin{tabular}{llll}
\hline & ANH & Non-ANH & P \\
\hline & & & \\
$\mathrm{n}$ & 14 & 14 & \\
Sex, F/M & $10 / 4$ & $1 \mathrm{I} / 3$ & 1.00 \\
Age, yr & $75.8(6.4)$ & $70.1(9.6)$ & 0.08 \\
Weight, kg & $75(11.5)$ & $76(13.2)$ & $0.8 \mathrm{I}$ \\
Height, cm & $166(8)$ & $166(10)$ & 0.98 \\
ASA (median (range)) & $2(1-2)$ & $2(1-2)$ & 0.75 \\
Mean arterial blood pressure, & $103(12)$ & $118(19)$ & $0.02^{*}$ \\
mmHg & & & \\
Total blood volume, mL & $447 I(809)$ & $4446(736)$ & 0.93
\end{tabular}

ANH: Acute normovolaemic hemodilution; non-ANH: No acute normovolaemic hemodilution; Mean (SD) * significance

Table 2: Perioperative values for the patients.

\begin{tabular}{|c|c|c|c|}
\hline & ANH I4 & Non-ANH I4 & $\mathrm{P}$ \\
\hline $\begin{array}{l}\text { Mean arterial blood pressure, } \\
\mathrm{mmHg}\end{array}$ & $47.9(1.8)$ & $49.0(3.6)$ & 0.31 \\
\hline Central vein pressure, $\mathrm{mmHg}$ & $4.5(2)$ & $6.1(4)$ & 0.21 \\
\hline Duration of surgery, min & $93(13)$ & $100(20)$ & 0.26 \\
\hline Duration of anaesthesia, min & $182(15)$ & $193(23)$ & 0.16 \\
\hline Duration of hypotension, min & $102(20)$ & $110(22)$ & 0.34 \\
\hline $\begin{array}{l}\text { Core temperature after surgery, } \\
\text { C }\end{array}$ & $36.5(0.4)$ & $36.7(0.7)$ & 0.20 \\
\hline Postoperative ICU-time, hrs & $6.8(1.2)$ & $7.1(0.8)$ & 0.36 \\
\hline
\end{tabular}

ANH: Acute normovolaemic hemodilution; non-ANH: No acute normovolaemic hemodilution; Mean (SD) * significance

Postoperatively in the recovery room, MAP was below 75 $\mathrm{mmHg}$ for $38 \mathrm{~min} \pm 40$ (ANH) vs. $52 \mathrm{~min} \pm 77$ (non- 
ANH) $(\mathrm{p}=0.56)$. Time used for anaesthesia (from patient enters the operating theatre to entering the recovery room) and duration of surgery was identical between groups. Core temperature on admission to the recovery room was also without a significant difference.

The preoperative donated blood volume was mean 877 $\mathrm{mL} \pm 175$, or $19.7 \%$ of the total blood volume. All blood was retransfused to ANH patients in the recovery room.

Perioperative blood loss and substitution are shown in Table 3. At almost all registrations there was a reduced blood loss in non-ANH group. Colloid substitution was in ANH group $679 \mathrm{~mL}$ and blood transfusion $386 \mathrm{~mL}$, without including the infusion of HAES used in the ANH procedure and the predonated amount of blood. Fifty percent in the ANH group received homologous blood transfusion during the hospital stay (771 mL pr. patient transfused) vs. 42 $\%$ in non-ANH group ( $800 \mathrm{~mL}$ pr. patient transfused) (ns). Numbers of units packed red cells are shown in Table 4 . No patients received blood components other than erythrocytes.

Table 3: Blood loss and substitution for the patients.

\begin{tabular}{|c|c|c|c|}
\hline & ANH 14 & Non-ANH I4 & $P$ \\
\hline Blood loss intraoperative, $\mathrm{mL}$ & |3| (78) & III (56) & 0.45 \\
\hline Blood loss I. postop. Hour, mL & $295(129)$ & $204(77)$ & $0.03^{*}$ \\
\hline Blood loss 2. postop. Hour, mL & $192(98)$ & II 8 (72) & $0.03^{*}$ \\
\hline Blood loss 3. postop. Hour, mL & $132(85)$ & 1||$(6 I)$ & 0.47 \\
\hline Blood loss 24. postop hours, $\mathrm{mL}$ & $1057(292)$ & $836(280)$ & $0.05^{*}$ \\
\hline Blood loss 2. postop day, mL & $109(78)$ & $83(67)$ & 0.36 \\
\hline Total blood loss, mL & $1306(300)$ & $1026(294)$ & $0.02^{*}$ \\
\hline $\begin{array}{l}\text { Homologous blood transfusion } \\
\text { (PRC), mL }\end{array}$ & $386(720)$ & $343(454)$ & 0.85 \\
\hline Crystalloid first 24 hours, $\mathrm{mL}$ & $3229(582)$ & $33 \mid 2(73 \mid)$ & 0.75 \\
\hline Colloid first 24 hours, $\mathrm{mL}$ & $679(575)$ & $377(36 I)$ & 0.12 \\
\hline Donated amount of blood, $\mathrm{mL}$ & $877(175)$ & & \\
\hline
\end{tabular}

ANH: Acute normovolaemic hemodilution; non-ANH: No acute normovolaemic hemodilution; Mean (SD) * significance

The perioperative blood analysis demonstrated, except from hematocrit at start and conclusion of surgery, no differences (Table 5).

There was no difference in time spent in hospital between the groups. At the 7'Th postoperative day all patients in this study were transferred to a hotel department for further mobilisation. During the hospital stay we did not observe any cases of renal failure according to the Creatinine measurements. All patients were discharged from the hospital alive.
Table 4: Patients receiving blood substitution (units of packed red cells).

ANH I4 Non-ANH I4 P

$\begin{array}{llll}\text { Zero } & 7 & 8 \\ \text { I unit } & 4 & 0 & \\ 2 \text { Units } & 1 & 4 & \\ 3 \text { Units } & 1 & 0 & \\ >3 \text { Units } & 1 & 2 & 0.85 \\ \text { Average transfused, } \mathrm{mL} & 386 & 343 & \end{array}$

ANH: Acute normovolaemic hemodilution; non-ANH: No acute normovolaemic hemodilution

Table 5: Perioperative blood measurements.

\begin{tabular}{llll}
\hline & ANH I4 & Non-ANH I4 & P \\
\hline & & & \\
Hematocrit preoperative, \% & $38.7(3)$ & $38.1(5)$ & 0.7 I \\
Hematocrit at start of surgery, \% & $30.4(5)$ & $38.1(5)$ & 0.00 I \\
& & & $*$ \\
Hematocrit I. hour postop, \% & $28.7(3)$ & $32(4)$ & $0.04^{*}$ \\
Hematocrit I. postop day, \% & $29.8(3)$ & $29.9(4)$ & 0.9 I \\
Hematocrit 2. postop day, \% & $30.7(3)$ & $29.9(4)$ & 0.63 \\
Hematocrit 3. postop day, \% & $30.4(3)$ & $28.8(2)$ & 0.14 \\
Hematocrit 5. postop day, \% & $29.4(3)$ & $30.3(4)$ & 0.53 \\
Platelet count preoperative, I06/I & $257(72)$ & $265(63)$ & 0.35 \\
Platelet count I. postop day, I06/ & $190(60)$ & $185(42)$ & $0.8 \mathrm{I}$ \\
I & & & \\
Platelet count 5. postop day, I06/ & $322(85)$ & $337(77)$ & 0.38 \\
I & & & \\
APTT preoperative, sec & $32(3)$ & $30(3)$ & 0.16 \\
Creatinine preoperative, mol/L & $83(2 \mathrm{I})$ & $85(23)$ & 0.79 \\
Creatinine I. postop.day, mol/L & $82(20)$ & $80(17)$ & 0.58 \\
Creatinine 5. postop day, mol/L & $80(22)$ & $74(13)$ & 0.39 \\
& & & \\
\hline
\end{tabular}

ANH: Acute normovolaemic hemodilution; non-ANH: No acute normovolaemic hemodilution; Mean (SD) * significance

\section{Discussion}

In both groups there was a remarkable low total blood loss, due to the anaesthetic technique used (HEA). The blood loss was, especially the non-ANH group, in a range identical with the result of our previous study comparing HEA with normotensive regional anaesthesia in TKR surgery [10]. ANH failed in the present study to demonstrate a reduced need for blood transfusion with homologous blood products during TKR surgery in HEA anaesthesia. We here use a moderate hemodilution (20\% of total blood volume) to a hematocrit near 30\% agreeing with the recommendations for patients at this age [11]. Despite of this $50 \%$ in the ANH group received homologous 
blood. In a previous ANH study without the use of HEA anaesthesia, $45 \%$ of TKR patients received homologous blood [12]. A case study analysis of patients who had undergone moderate ANH (15\% of patients blood volume) estimated that only 0.5 unit of blood is "saved" [13]. Mathematical models concur that savings are small unless profound hemodilution is accompanied by large blood loss (> 2 L) [14]. Another study postulates that the safety and efficacy of more extensive hemodilution is controversial because it is not possible for all patients and may provide only little additional blood conservation [15].

At almost all registrations the ANH group demonstrated an increased postoperative blood loss compared to the non-ANH group. Dilution of the blood after ANH is the most reasonable explanation to this. TKR surgery is known to be associated with extensive postoperative blood loss, probably because of difficulties in performing postoperative compression and haemostasis of the tissue in the knee [10]. This fact combined with the reduced viscosity of the blood could increase the postoperative blood loss. We did not register any difference in time spent in surgery or postoperative hypotension that could explain differences in the blood loss. In a previous study mild hypothermia was found to be correlated to a significantly increased blood loss in hip arthroplasty surgery [16]. We did not register differences in postoperative core temperature. Another possible explanation for the difference in blood loss could be alternation of the coagulation system because of the hemodilution. ANH is found to cause a slight coagulopathy including a decrease in platelet count, prothrombin time, fibrinogen, AT-III and plasminogen. Furthermore APTT is increased. The combination of $\mathrm{ANH}$ and prostaglandin E1 induced hypotension to $55 \mathrm{mmHg}$ did not alter the coagulation system any further [17]. Preand postoperative platelet count and APTT were in our study without significant differences. The registered difference in the mean age between the groups must be without significant influence on the perioperative blood loss. We found no complications related to the brain or the heart during the hospital stay. In a recently published work, HEA demonstrates identical rates of cardiac and thromboembolic complications in elderly patients compared to normotensive epidural anaesthesia. Furthermore, there were no differences in early or long-term cognitive dysfunction [18]. None of the patients died in the perioperative period, in agreement with the very low mortality described by Sharrock [7].

\section{Conclusions}

HEA is found to reduce the perioperative blood loss and the need for transfusion compared to conventional anaesthesia $[9,10]$, but the combination of HEA and ANH seems in this study to be without any further benefits regarding the blood loss and need for transfusion.

\section{Competing Interests}

None declared.

\section{Author contributorship}

All three authors carried out the protocol, inclusion of patients, anaesthesia and data collections.

PJ wrote the primary manuscript and performed the statistical analysis. MBM and UTL were rewriting the primary manuscript.

All authors read and approved the final manuscript.

\section{References}

I. Consensus conference. Perioperative red blood cell transfusion. JAMA 1988, 260:2700-2703

2. Dufy $G$, Neal KR: Differences in post-operative infection rates between patients receiving autologous and homologous blood transfusion: a meta-analysis of published randomized and nonrandomized studies. Transfus Med 1996, 6(4):325-328

3. Stehling L, Zauder HL: Acute normovolemic hemodilution. Transfusion |991, 3 1:857-868

4. Goodnough LT, Monk TG, Brecher ME: Acute normovolemic hemodilution should replace the preoperative donation of autologous blood as a method of autologous-blood procurement. Transfusion 1998, 38(5):473-476

5. Sharrock NE, Mineo R, Urquhart B: Hemodynamic effects of low dose epinephrine and sodium nitroprusside during epidural hypotensive anesthesia. Reg Anesth 1989, I4:SI2

6. Sharrock NE, Mineo R, Urquhart B: Haemodynamic effects and outcome analysis of hypotensive extradural anaesthesia in controlled hypertensive patients undergoing total hip arthroplasty. $\mathrm{Br}$ J Anaesth 1991, 67:17-25

7. Sharrock NE, Cazan MG, Hargett MJL, Williams-Russo P, Wilson PD: Changes in mortality after total hip arthroplasty over a tenyear period. Anesth Analg 1995, 80:242-248

8. Sharrock NE, Bading B, Mineo R, Blumenfeld JD: Deliberate hypotensive epidural anesthesia for patients with normal and low cardiac output. Anesth Analg 1994, 79:899-904

9. Sharrock NE, Mineo R, Urquhart B: The effect of two levels of hypotension on intraoperative blood loss during total hip arthroplasty performed under lumbar epidural anesthesia. Anesth Analg 1993, 76:580-584

10. Juelsgaard P, Larsen UT, Sørensen JV, Madsen F, Søballe K: Hypotensive Epidural Anesthesia in Total Knee Replacement without Tourniquet. Reduced blood loss and transfusion. Reg Anesth 200 I, 26(2): 105-II0

II. Spahn DR, Zollinger A, Schlumpf RB, Stöhr S, Seifert B, Schmid ER, Pasch T: Hemodilution tolerance in elderly patients without known cardiac disease. Anesth Analg 1996, 82:68I-686

12. Goodnough LT, Merkel K, Monk TG: A randomized trial of acute normovolemic hemodilution compared to preoperative autologous blood donation in total knee arthroplasty. Vox Sang 1999, 77:11-16

13. Goodnough LT, Bravo J, Hsueh Y, Keating L, Brittenham GM: Red blood volume in autologous and homologous units; Implications for risk/benefit assessment for autologous blood "crossover" and directed blood transfusion. Transfusion 1989, 29:82।-822

14. Feldman JM, Roth JV, Bjoraker DG: Maximum blood savings by acute normovolemic hemodilution. Anesth Analg 1995, 80:108113

15. Brecher ME, Rosenfeld M: Mathematical and computer modeling of acute normovolemic hemodilution. Transfusion 1994, 34:176-179

16. Schmied H, Kurz A, Sessler DL, Kozek S, Reiter A: Mild hypothermia increases blood loss and transfusion requirements during total hip arthroplasty. Lancet 1996, 347(8997):289-292

17. Fukusaki M, Maekawa T, Miyako M, Niiya S, Sumikawa K: Acute haemodilution and prostaglandin El-induced hypotension: 
effects on the coagulation-fibrinolysis system. Eur J Anaesthesiol I997, I 4(4):443-9

18. Williams-Russo P, Sharrock NE, Mattis S, Liguori GA, Mancuso C, Peterson MG, Hollenberg J, Ranawat C, Salveti E, Sculco T: Randomized trial of hypotensive epidural anesthesia in older adults. Anesthesiology 1999, 91 1:926-935

\section{Pre-publication history}

The pre-publication history for this paper can be accessed here:

http://www.biomedcentral.com/1471-2253/2/1/prepub

Publish with BioMed Central and every scientist can read your work free of charge

"BioMedcentral will be the most significant development for disseminating the results of biomedical research in our lifetime." Paul Nurse, Director-General, Imperial Cancer Research Fund

Publish with BMC and your research papers will be:

- available free of charge to the entire biomedical community

- peer reviewed and published immediately upon acceptance

- cited in PubMed and archived on PubMed Central

- yours - you keep the copyright 